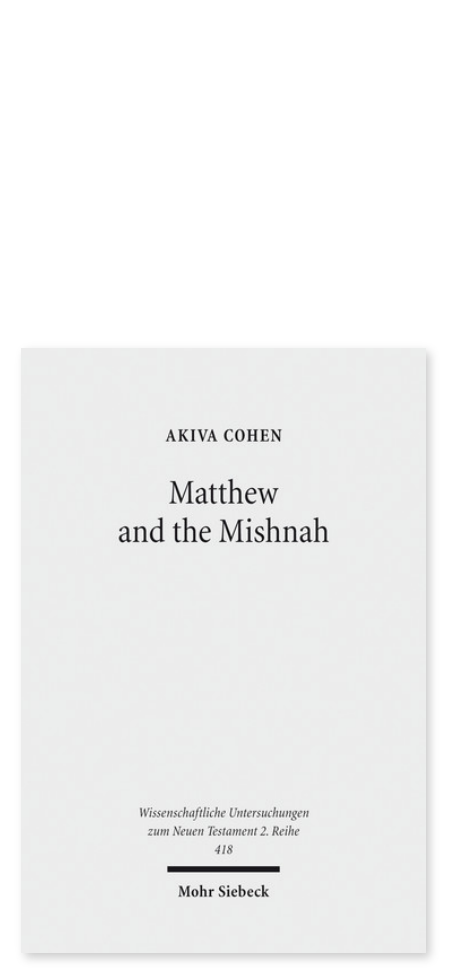

2016. XIX, 636 Seiten. WUNT II 418

ISBN 978-3-16-154810-9

DOI 10.1628/978-3-16-154810-9

eBook PDF 139,00€

ISBN 978-3-16-149960-9

fadengeheftete Broschur 139,00€

\section{Akiva Cohen}

\section{Matthew and the Mishnah}

Redefining Identity and Ethos in the Shadow of the Second Temple's Destruction

[Matthäus und die Mischna. Die Neudefinition von Identität und Ethos im Schatten der Zerstörung des Zweiten Tempels.]

Veröffentlicht auf Englisch.

Akiva Cohen untersucht die allgemeine Forschungsfrage: Wie rekonstruieren die Verfasser religiöser Texte die Identität und das Ethos ihrer Gemeinde, wenn der zentrale Kult fehlt? Sein besonderer sozio-historischer Fokus bei dieser allgemeinen Frage ist: Wie haben die Autoren des Matthäusevangeliums und der bzw. die Herausgeber der Mischna ihre Gruppenidentität nach der Zerstörung des Zweiten Tempels neu definiert? Cohen untersucht des Weiteren, wie sowohl die matthäischen als auch die mischnischen Gemeinden sich als Gemeinschaft neu orientierten und durch die grundlegenden Texte ihrer jeweiligen Autoren bzw. Redaktoren neue Visionen artikulierten. Der Kontext dieser Studie ist also der eines innerjüdischen Phänomens; zwei jüdische Gruppierungen versuchen, ihre gemeinschaftliche Identität und ihr Ethos ohne den materiellen Tempel, der das kultische Zentrum ihres Kosmos gewesen war, (neu) zu begründen.

Akiva Cohen Born 1960; Bachelor of Religious Studies, Tyndale College, Toronto, Canada; Master of Arts, Trinity International University, Deerfield, III., USA; 2008 PhD, Tel Aviv University, Israel; has taught New Testament studies at Jerusalem University College, and Ben Gurion University in the Deichmann Program for Jewish and Christian Literature of the Hellenistic-Roman Era, Israel.

Jetzt bestellen:

https://mohrsiebeck.com/buch/matthew-and-the-mishnah-9783161548109?no_cache=1

order@mohrsiebeck.com

Telefon: +49 (0)7071-923-17

Telefax: $+49(0) 7071-51104$ 